\title{
Gentamicin and tobramycin compared in the treatment of mucoid pseudomonas lung infections in cystic fibrosis
}

\author{
A J MARTIN, CHRISTINE A SMALLEY, R H GEORGE, D E HEALING, AND \\ CHARLOTTE M ANDERSON
}

Institute of Child Health, University of Birmingham, and the Department of Bacteriology, Birmingham Children's Hospital

SUMMARY 18 children with cystic fibrosis and mucoid pseudomonas lung infection were treated with courses either of gentamicin plus carbenicillin, or tobramycin plus carbenicillin, with 2 children each receiving two courses. 10 courses of gentamicin at a dose of $9 \mathrm{mg} / \mathrm{kg}$ per day plus carbenicillin at $800 \mathrm{mg} / \mathrm{kg}$ per day, and 10 courses of tobramycin at $9 \mathrm{mg} / \mathrm{kg}$ per day plus carbenicillin at $800 \mathrm{mg} / \mathrm{kg}$ per day were given. There was clinical and $x$-ray improvement in both groups of children, but there was no difference between the therapeutic benefit of either regimen. Pseudomonas aeruginosa was not cultured at the end of treatment after 15 of the 20 courses, but it returned in all but one patient within 3 months. Neither ototoxicity nor renal damage with these high doses of aminoglycoside was detected. $P$. aeruginosa had not been eliminated when 9 of these patients earlier had received courses of gentamicin in a dose of $6 \mathrm{mg} / \mathrm{kg}$ per day plus carbenicillin at $800 \mathrm{mg} / \mathrm{kg}$ per day. The results show that $P$. aeruginosa can successfully be eliminated or suppressed with high-dose aminoglycoside plus carbenicillin, but such elimination is usually short lived.

Staphylococcal lung infection in cystic fibrosis (CF) is well recognised but in recent years Pseudomonas aeruginosa has been noted increasingly as a lung pathogen. Since 1963 Mearns $^{1}$ has found an increased isolation rate of $P$. aeruginosa in severely affected patients, and a concomitant decrease in Staphylococcus aureus lung infection.

At present $\boldsymbol{P}$. aeruginosa appears to be the most common pathogen isolated from the respiratory tract of patients with $\mathrm{CF}^{2}$ The frequency of its isolation has varied between centres, with Wood et al. ${ }^{3}$ reporting a figure of $70-80 \%$, Mearns et al. ${ }^{4}$ giving a figure of $28 \%$, while McCrae et al..$^{5}$ gave a figure of only $18 \%$. The experience of the CF clinic at Birmingham Children's Hospital is that about $48 \%$ of patients have $P$. aeruginosa repeatedly cultured from their sputum or cough swabs, and in about $20 \%$ a mucoid $P$. aeruginosa is present. The transition of pseudomonas to the mucoid form has been associated with increased severity of lung disease. ${ }^{6}$ It is now believed by many workers that mucoid organisms are more pathogenic than nonmucoid forms and consequently many therapeutic regimens using inhaled or parenteral antibiotics have been devised for the treatment of this organism. ${ }^{7-11}$
Recently the aminoglycoside antibiotic tobramycin has been used in the treatment of $\boldsymbol{P}$. aeruginosa in CF by four groups of workers ${ }^{5-14}$ but in none of these studies was there a comparative trial with other antibiotics. We report here a trial comparing tobramycin with gentamicin; each was given intravenously with carbenicillin.

\section{Methods}

Children attending our clinic were chosen for treatment. Each child had increased sweat electrolyte levels and characteristic gastrointestinal and pulmonary disease. 18 children (representing approximately one-sixth of all clinic patients) whose condition was considered to be deteriorating with mucoid $P$. aeruginosa infection despite outpatient treatment were studied. Deterioration was manifested by general ill health, weight loss, decreasing exercise tolerance, increased cough, and increasing volumes of purulent sputum. The patients were allocated alternately into one of two groups and received either tobramycin plus carbenicillin or gentamicin plus carbenicillin. Patients with organisms resistant to carbenicillin were excluded. 
14 patients were treated for 14 days, 2 patients for 13 days ( 1 from each group), and 2 patients for 11 days (both gentamicin group). Either gentamicin or tobramycin was given intravenously as an 8-hourly bolus dose via an indwelling intravenous cannula. The starting dose of both antibiotics was $9 \mathrm{mg} / \mathrm{kg}$ per day in 3 divided doses. Blood levels of the aminoglycoside antibiotic were measured on days 1,4 , and 8 , and any adjustment to dosage was carried out on the basis of these results. Blood was taken immediately before and 10 minutes after an intravenous bolus injection. Carbenicillin was given to each patient in a dose of $800 \mathrm{mg} / \mathrm{kg}$ per day in divided 6-hourly doses by intravenous infusion, and probenecid was used routinely. Colomycin by inhalation was given in all instances, in a dose of 125000 units to children up to age of 5 years, 250000 units to children from 5 to 12 years, and 500000 units to children over 12 years. Vigorous physiotherapy was given 3 times a day to all patients.

The clinical state of each patient was assessed initially and throughout the treatment period using our own scoring system.* General health, cough, amount of sputum, quality of sputum, and dyspnoea were the five parameters examined and each was scored numerically and summated to give an overall value. $X$-rays of the chest were made before and after treatment and the films were assessed by the scoring method of Chrispin and Norman ${ }^{15}$ modified because lateral chest $x$-rays were not always available. Blood urea was measured and audiometry carried out on each patient before and after treatment.

The minimum inhibitory concentrations (MIC) of gentamicin, tobramycin, and carbenicillin were determined on pretreatment isolates of mucoid $\boldsymbol{P}$. aeruginos $a$ and the first post-treatment isolate by an agar dilution method using DST agar (Oxoid) with an inoculum of $10^{5}$ colony-forming units. Each day all the sputum expectorated was collected for volume measurement, culture, and determination of

* Details of our clinical scoring system are available from authors. antibiotic levels by a plate diffusion method using Bacillus subtilis var globigii incorporated into antibiotic assay medium No 5 (Difco) with added beta lactamase (Whatman) to destroy carbenicillin. Standards were prepared in $0.01 \mathrm{mmol} / 1$ phosphate buffer $\mathrm{pH} 7 \cdot 8$. Antibiotic levels in blood were determined similarly using klebsiella Southmead incorporated in DST agar (Oxoid) with standards prepared in serum.

Bacteriocine typing was carried out on the isolates of mucoid $P$. aeruginosa at the start of treatment and on subsequent isolates after treatment using bacteriocine extracts produced by the methods of Williams and Govan..$^{16}$

Each patient was reviewed regularly after treatment, and an attempt was made to evaluate the duration of any improvement beyond the immediate post-treatment period by examining the time taken for sputum volume to return to pretreatment level.

\section{Results}

These are summarised in Tables 1-3. In Table 1 the two groups of patients are compared before, during, and after treatment. There was no difference in age in the two groups, which ranged from 3 years 10 months to 11 years 7 months. Both groups had clinical and $x$-ray scores that were similar before starting treatment.

Equality of treatment was assessed by peak serum levels of antibiotic which were found to be similar in both groups. Although the initial dosage was governed by the protocol, in 1 patient (in the tobramycin group) the dose had to be reduced, and in 2 patients (in the gentamicin group) the dose had to be increased in the light of serum levels.

After treatment there was a similar highly significant improvement in clinical $(P<0.001)$ and $x$-ray $(P<0.001)$ scores in the two groups, using the $t$ test for grouped data. One child in the tobramycin group, who had a very poor clinical score, died during treatment. Statistical analyses were made with and

Table 1 Comparison of the two treatment groups before, during, and after treatment

\begin{tabular}{|c|c|c|c|c|c|c|c|c|}
\hline & \multicolumn{3}{|c|}{$\begin{array}{l}\text { Gentamicin + carbenicillin } \\
(n=10)\end{array}$} & \multicolumn{3}{|c|}{$\begin{array}{l}\text { Tobramycin + carbenicillin } \\
(n=10)\end{array}$} & \multicolumn{2}{|c|}{$\begin{array}{l}\text { Statistical comparison } \\
\text { ( } \text { tests for ungrouped data })\end{array}$} \\
\hline & Range & Mean & $S D$ & Range & Mean & $S D$ & & \\
\hline $\begin{array}{l}\text { Before treatment } \\
\text { Clinical scores } \\
\text { Modified } x \text {-ray scores }\end{array}$ & $\begin{array}{l}9-20 \\
8-23\end{array}$ & $\begin{array}{l}15 \cdot 8 \pm \\
13 \cdot 9 \pm\end{array}$ & $\begin{array}{l}3 \cdot 54 \\
5 \cdot 1\end{array}$ & $\begin{array}{r}7-20 \\
12-26\end{array}$ & $\begin{array}{l}13 \pm \\
16 \cdot 4 \pm\end{array}$ & $\begin{array}{l}5 \cdot 4 \\
4 \cdot 1\end{array}$ & $\begin{array}{l}P>0.1 \\
P>0.9\end{array}$ & $\begin{array}{l}\text { NS } \\
\text { NS }\end{array}$ \\
\hline $\begin{array}{l}\text { During treatment } \\
\text { Peak blood drug levels }(\mu \mathrm{g} / \mathrm{ml})\end{array}$ & $5 \cdot 8-16$ & $11 \cdot 2 \pm$ & $2 \cdot 7$ & $2 \cdot 7-18$ & $10 \cdot 4 \pm$ & 3.4 & $\mathbf{P}>0.3$ & NS \\
\hline $\begin{array}{l}\text { After treatment } \\
\text { Clinical scores } \\
\text { Modified } x \text {-ray score }\end{array}$ & $\begin{array}{r}22-28 \\
5-20\end{array}$ & $\begin{array}{l}25 \cdot 3 \pm \\
11 \cdot 8 \pm\end{array}$ & $\begin{array}{l}1 \cdot 8 \\
5 \cdot 2\end{array}$ & $\begin{array}{r}17-28 \\
7-19\end{array}$ & $\begin{array}{l}21 \cdot 7 \pm \\
11 \cdot 5 \pm\end{array}$ & $\begin{array}{l}8 \cdot 0 \\
4 \cdot 0\end{array}$ & $\begin{array}{l}P>0.2 \\
P>0.9\end{array}$ & $\begin{array}{l}\text { NS } \\
\text { NS }\end{array}$ \\
\hline
\end{tabular}


Table 2 Relationship of tobramycin level in sputum to sensitivity of organism and bacteriological outcome

\begin{tabular}{lllllllllll}
\hline \multicolumn{1}{c}{ Patients } \\
\hline & 1 & 2 & 3 & 4 & 5 & 6 & 7 & 8 & 9 & 10 \\
\cline { 2 - 8 } & 0.5 & 0.5 & 0.5 & 1.0 & 0.5 & 0.5 & 0.5 & 0.5 & 0.5 & 0.5 \\
$\begin{array}{c}\text { MIC of tobramycin } \\
(\mathrm{mg} / 1)^{*}\end{array}$ \\
$\begin{array}{c}\text { Highest sputum } \\
\text { level (mg/1) }\end{array}$ & 0.4 & 0.6 & 1.6 & 1.3 & 0.9 & 2.4 & 1.3 & - & - & - \\
$\begin{array}{c}\text { Pseudomonas } \\
\text { suppressed }\end{array}$ & Yes Died & Yes & No & No & Yes Yes Yes Yes Yes \\
\hline
\end{tabular}

* Minimum inhibitory concentration (MIC) of tobramycin to patient's pretreatment isolate of mucoid $P$. aeruginosa.

Table 3 Relationship of gentamicin level in sputum to sensitivity of organism and bacteriological outcome

\begin{tabular}{llllllllllll}
\hline \multicolumn{11}{c}{ Patients } \\
\hline & 1 & 2 & 3 & 4 & 5 & 6 & 7 & 8 & 9 & 10 \\
\cline { 2 - 8 } & 2 & 2 & 2 & 2 & 2 & 1 & 2 & 0.5 & 1 & 1 \\
$\begin{array}{c}\text { MIC of gentamicin } \\
\left(\mathrm{mg} / \mathbf{l}^{*}\right.\end{array}$ & 0.2 & 1.6 & 0.6 & 0.6 & 0.6 & 1.5 & 0.7 & 1.1 & 0.4 & - \\
$\begin{array}{c}\text { Highest sputum } \\
\text { level (mg/l) }\end{array}$ & Yes No & Yes & Yes & Yes & Yes No & Yes Yes Yes \\
suppressed & * MIC of gentamicin to patient's pretreatment isolate of mucoid $P$. \\
aeruginosa. &
\end{tabular}

without this child, with little difference in the results. The analyses given include this child.

In vitro studies showed gentamicin to be 2 - to 4 -fold less active against isolates of mucoid $P$. aeruginosa than tobramycin. The MIC to tobramycin ranged from 0.5 to $1 \mathrm{mg} / 1$ (Table 2) and from 0.5 to $2 \mathrm{mg} / 1$ for gentamicin (Table 3). These tables also show the lack of correlation between the sputum level and bacteriological response. $P$. aeruginosa was not eliminated in 4 patients at the end of treatment ( 2 in each group); in 6 patients ( 3 in each group) it was eliminated for one month, and in 4 patients ( 3 in the gentamicin group) it was eliminated for 2 months after treatment. In 4 patients (one in the gentamicin group) the sputum was free of $P$. aeruginosa for 3 months, and in one patient in the gentamicin group for 15 months. Four patients were recolonised by different bacteriocine types ( 2 in each group). The duration of freedom from pseudomonas after treatment did not correlate with age of the patient, clinical score, or the total duration of infection with the organism before treatment. Sputum volume took 3 to 4 months to return to pretreatment levels in either group.

In no patient was there evidence of ototoxicity or renal damage as judged by audiometry and blood urea measurements before and after treatment. Subsequent audiograms at periods up to 2 years have not shown delayed ototoxicity.

\section{Discussion}

This study shows that despite a 2- to 4-fold greater activity of tobramycin in vitro compared with gentamicin, $C F$ patients with mucoid $P$. aeruginosa lung infections responded equally well to either antibiotic if combined with carbenicillin. Both groups of patients improved significantly as judged by clinical and $x$-ray assessment. Bacteriological response did not correlate with sputum level of antibiotic but it should be noted that peak levels were not determined, as assays were performed on 24-hour collections of sputum.

Bacteriocine typing would suggest true elimination of $P$. aeruginosa in the 4 patients recolonised by different bacteriocine types. In patients in whom $P$. aeruginosa was eliminated but returned as the same bacteriocine type, it is difficult to know if this represents complete eradication with subsequent reinfection or was merely suppression. However before the trial 9 of the patients had received 17 courses of intravenous gentamicin at a dosage of 6 $\mathrm{mg} / \mathrm{kg}$ per day in combination with carbenicillin at $800 \mathrm{mg} / \mathrm{kg}$ per day. In each case mucoid $P$. aeruginosa had still persisted in the sputum at the end of the 2week course. However, when the higher dose of $9 \mathrm{mg}$ / $\mathrm{kg}$ per day combined with carbenicillin was used in the same patients, 8 out of 11 courses rendered them $P$. aeruginosa-free at the end of treatment. One patient had received 5 courses of gentamicin and carbenicillin previously at the lower gentamicin dose without the organisms being eliminated but subsequently received a course of gentamicin and carbenicillin and another course of tobramycin and carbenicillin, both at $9 \mathrm{mg} / \mathrm{kg}$ per day, with negative sputum cultures at the end of each treatment.

Govan $^{17}$ pointed out that carbenicillin may stabilise the mucoid form of $P$. aeruginosa. It is not known whether this is important, but in our experience the aminoglycoside antibiotics are more effective against mucoid strains when they are used in combination with carbenicillin. If gentamicin or tobramycin is given in a dose of $9 \mathrm{mg} / \mathrm{kg}$ per day without carbenicillin there is good initial clinical improvement but it is not sustained, and only a few patients are free of mucoid $P$. aeruginosa in their sputum at the end of treatment. Those patients in whom the organisms are not found after treatment are subsequently all recolonised by the same bacteriocine types, suggesting that true elimination may not have occurred.

Mearns et $a l .{ }^{4}$ and Hoiby ${ }^{18}$ pointed out that $P$. aeruginosa in the mucoid form follows chronic $P$. aeruginosa infection in a nonmucoid form and appears in the more severely affected patients. Whether this organism is responsible for the 
deterioration of lung function or whether it represents an opportunistic pathogen in an already severely damaged lung is unknown. The treatments given have produced both radiological and clinical improvement, with bacteriological suppression for short periods in three-quarters of our cases.

We can speculate whether long-term benefit from repeated intravenous courses of these antibiotics in high doses may slow the rate of deterioration of lung function. We note that it took 3 to 4 months for sputum levels to return to pretreatment volumes and this supports the view that regular treatment every 3 to 4 months in patients with mucoid pseudomonas infections would slow the deterioration of lung disease. We currently consider that the evidence in favour of regular treatment is not sufficiently convincing to warrant its implementation if the patient otherwise feels well. It remains our policy to use intravenous antibiotics if there is evidence of clinical deterioration with mucoid $P$. aeruginosa infection. Using this criterion, children with such infection will receive a course of intravenous antibiotics, on average, about once a year, and this is acceptable both to patients and parents.

\section{References}

1 Mearns M B. Treatment and prevention of pulmonary complications of cystic fibrosis in infancy and early childhood. Arch Dis Child 1972; 47: 5-11.

2 Hoiby N. Epidemiological investigations of the respiratory tract bacteriology in patients with cystic fibrosis. Acta Pathol Microbiol Scand (B) 1974; 82: 541-50.

3 Wood R E, Boat T F, Doershuk C F. State of the artcystic fibrosis. Am Rev Respir Dis 1976; 113: 833-78.

- Mearns H B, Hunt G H, Rushworth R. Bacterial flora of the respiratory tract in patients with cystic fibrosis, 1950-1971. Arch Dis Child 1972; 47: 902-7.

5 McCrae W M, Raeburn J A, Hanson E J. Tobramycin therapy of infections due to Pseudomonas aeruginosa in patients with cystic fibrosis: effect of dosage and concentrations of antibiotics in sputum. $J$ Infect Dis 1976; 134: Supplement, 191-3.
6 Burns M W, May J R. Bacterial precipitins in serum of patients with cystic fibrosis. Lancet 1968; i: 270-2.

7 Anderson C M, Goodchild M C, eds. The Cystic Fibrosis Trust manual of diagnosis and management. Oxford: Blackwell Scientific, 1976: chapter 5, 51-75.

8 Parry M F, Neu H C, Merlino M, Gaeran P F, Ores C N, Denning C R. Treatment of pulmonary infections in patients with cystic fibrosis: a comparative study of ticarcillin and gentamicin. J Pediatr 1977; 90: 144-8.

9 Boxerbaum B, Pittman S, Doershuk C F, Stern R C, Matthews L W. Use of gentamicin in children with cystic fibrosis. J Infect Dis 1971 ; 124: Supplement, 293-5.

10 Huang N N, Hiller E J, Macri C M, Capitanio M, Cundy K R. Carbenicillin in patients with cystic fibrosis: clinical pharmacology and therapeutic evaluation. $J$ Pediatr 1971; 78: 338-45.

11 Marks M I, Prentice R, Swarson R, Cotton E K, Eickhoff T C. Carbenicillin and gentamicin: pharmacologic studies in patients with cystic fibrosis and pseudomonas pulmonary infections. J Pediatr 1977; 79: 822-8.

12 Hoff G E, Schiotz P O, Paulsen J. Tobramycin treatment of Pseudomonas aeruginosa infections in cystic fibrosis. Scand J Infect Dis 1974; 6: 333-7.

13 Hawley H B, Lewis R M, Swartz D R, Gump D W. Tobramycin therapy of pulmonary infections in patients with cystic fibrosis. Curr Ther Res 1974; 16: 414-23.

14 Crozier D N, Khan S R. Tobramycin in the treatment of infections due to Pseudomonas aeruginosa in patients with cystic fibrosis. J Infect Dis 1976; 134: Supplement, 187-90.

15 Chrispin A R, Norman A P. The systematic evaluation of the chest radiograph in cystic fibrosis. Pediatr Radiol 1974 ; 2 : 101-6.

16 Williams R J, Govan J R W. Pyocine typing of mucoid strains of Pseudomonas aeruginosa isolated from children with cystic fibrosis. J Med Microbiol 1973; 6: 409-12.

17 Govan J R W. Letter: Antibiotic therapy and cystic fibrosis: increased resistance of mucoid Pseudomonas aeruginosa to carbenicillin. J Antimicrob Chemother 1976; 2: 215-6.

18 Hoiby N A. Pseudomonas aeruginosa infection in cystic fibrosis. Relationship between mucoid strains of Pseudomonas aeruginosa and the humoral immune response. Acta Pathol Microbiol Scand (B) 1974; 82 : 551-8.

Correspondence to Dr Christine A Smalley, The Children's Hospital, Ladywood Middleway, Ladywood, Birmingham B16 8ET.

Received 8 August 1979 